REVISTAS DE LA FAHCE

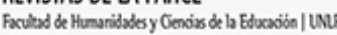

${ }^{2}{ }^{2}=$
Educación Física y Ciencia

ISSN: 1514-0105

ISSN: 2314-2561

revistaefyc@fahce.unlp.edu.ar

Universidad Nacional de La Plata

Argentina

\title{
Repensando um modelo de classificação dos jogos esportivos uma proposta inicial
}

\author{
Canan, Felipe \\ Repensando um modelo de classificação dos jogos esportivos - uma proposta inicial \\ Educación Física y Ciencia, vol. 22, núm. 1, 2020 \\ Universidad Nacional de La Plata, Argentina \\ Disponible en: http://www.redalyc.org/articulo.oa?id=439963095005 \\ DOI: https://doi.org/10.24215/23142561e113
}

Esta obra está bajo una Licencia Creative Commons Atribución-NoComercial-Compartirlgual 4.0 Internacional. 


\title{
Repensando um modelo de classificação dos jogos esportivos - uma proposta inicial
}

Rethinking a classification model of sports games - an initial proposal

Felipe Canan

Universidade Federal de Mato Grosso, Brasil

felipe.canan@gmail.com

\author{
DOI: https://doi.org/10.24215/23142561e113 \\ Redalyc: http://www.redalyc.org/articulo.oa? \\ id $=439963095005$
}

Recepción: 15 Diciembre 2018

Aprobación: 05 Diciembre 2019

\begin{abstract}
Resumo:
Considerando a crescente criação/difusão de jogos esportivos, muitos dos quais bastante peculiares, objetivou-se realizar um exercício de revisão teórica de classificações que procuram agrupá-los tendo em conta aspectos relativos às respectivas lógicas internas. Tratou-se de uma pesquisa teórica que, além de uma discussão conceitual sobre esporte e jogos esportivos e da realização de um inventário destes jogos, adotou como ponto de reflexão a análise de alguns jogos esportivos que apresentam um caráter particular. Percebeu-se a necessidade de conjugação e ajustes nas classificações já existentes, modificando-se algumas nomenclaturas e acrescentando-se algumas categorias e subcategorias de jogos esportivos.
\end{abstract}

Palavras-chave: Esporte, Jogos esportivos, Praxiologia motriz, Teaching games for understanding.

\begin{abstract}
:
Considering the growing creation and diffusion of sports games -many of them quite peculiar- this text was aimed to carry out an exercise of theoretical revision of the classifications that seek to group the sports games taking into account aspects related to their respective internal logic. This paper was a theoretical research that, apart from presenting a discussion about the concept of sport and sports games and the accomplishment of an inventory of these games, adopted as a point of reflection the analysis of some sports games that present a particular character. The need of conjugation and adjustments in the existing classifications was noticed, such as modifying some nomenclatures and adding some categories and subcategories of sports games.
\end{abstract}

KEYWORDS: Sport, Sports games, Motor praxeology, Teaching games for understanding.

\section{INTRODUÇÃ̃o}

A adoção de sistemas de classificação de jogos esportivos dá-se por duas razões essenciais: uma intrínseca, com um fim em si mesma, em que se busca conhecer as características essenciais de cada jogo, que, por sua vez, contribuem para se compreender as respectivas lógicas internas (dinâmicas de funcionamento) a partir de critérios preconcebidos (Parlebas, 2001; González e Bracht (2012); Hernández Moreno, 2005); e outra extrínseca ou instrumental, que, tendo em vista o ensino em programas/currículos educacionais, busca agrupar os jogos de acordo com características semelhantes (ou lógica interna funcional semelhante), a fim de proporcionar uma generalização/diversificação de conteúdos e a superação de um currículo restrito a alguns jogos (talvez) mais tradicionais (Almond, 1986b; Ellis citada em Almond, 1986b).

Embora distintas, as razões não são antagônicas, mas sim complementares. Partindo de uma finalidade teórica ou de uma finalidade prática, no fim das contas, ambas tanto contribuem, para uma melhor compreensão dos jogos esportivos a partir de uma perspectiva comparada, quanto oferecem subsídios para uma intervenção prática mais qualificada, seja frente a um jogo esportivo específico, seja frente a um conjunto ou ao total de jogos esportivos.

Dentre os sistemas de classificação identificados na literatura, que levam em conta tais perspectivas, encontram-se principalmente os apresentados por Parlebas $(2001)^{1}$ e Hernández Moreno (2005) ${ }^{2}$, a partir 
do marco teórico da Praxiologia Motriz, e os apresentados por Almond (1986b) e Ellis (citada em Almond, 1986b), a partir do marco teórico-prático do Teaching Games For Understanding (TGFU).

Em contexto brasileiro, encontram-se nas classificações apresentadas por González (2006) e González e Bracht (2012), importantes marcos. Percebe-se nas classificações apresentadas por estes autores um esforço de interpretação e, em alguma medida, conjugação das demais classificações apresentadas, ainda que não se restrinjam a estas. As classificações apresentadas por González (2006) e González e Bracht (2012) ganham importância a partir do momento em que se percebem suas influências em importantes documentos da Educação Física brasileira, tais como o Referencial Curricular para Educação Física do Estado do Rio Grande do Sul (González e Fraga, 2009), a Base Curricular Comum Curricular da Educação Física para o Ensino Fundamental (Ministério da Educação, 2017) e os Cadernos Pedagógicos do Programa Segundo Tempo (González, Darido e Oliveira, 2017a, 2017b), um dos principais programas esportivos implementados pelo Governo Federal. Independentemente de tais documentos albergarem conhecimentos e propostas consensuais ou não em meio à comunidade da Educação Física brasileira, tratam-se de materiais que formalizaram e/ou institucionalizaram uma concepção/vertente teórica específica.

Levando-se em conta que cada classificação parte de diferentes pressupostos de equiparação/comparação entre jogos esportivos; que nenhuma delas mostra-se isenta de problemas (ou é muito abrangente e acaba agrupando jogos esportivos muito distintos ou é muito específica e acaba deixando de englobar alguns jogos esportivos); que a análise comparativa de diferentes jogos esportivos contribui para compreensão da lógica interna de cada qual; e que se tem pensado em um processo de diversificação dos jogos esportivos nos programas/currículos educacionais, traçou-se como objetivo deste artigo, realizar um exercício de revisão teórica de classificações de jogos esportivos adotando como ponto de reflexão a análise de alguns daqueles que apresentam um caráter peculiar, pouco ou não condizente com as classificações existentes.

Para complementar o exercício de revisão das classificações, buscou-se inicialmente discutir o próprio conceito de esporte e de jogos esportivos, que se mostram pouco claros ou, ao menos, pouco pacificados na literatura $^{3}$, e posteriormente apresentar um inventário de jogos esportivos, fruto de pesquisas do autor em materiais científicos (artigos, livros, teses, dissertações e monografias) e não científicos (livros e internet), ao longo de vários anos. Além da curiosidade e interesse científico, tal inventário diz respeito a um processo contínuo e gradual de pesquisa do autor tendo como pano de fundo a preparação para disciplinas na formação superior em Educação Física e cursos de extensão, ambos na área de jogos esportivos não tradicionais.

O texto assume-se enquanto uma pesquisa teórica, apresentada por Demo (1994 e 2000) como aquela que dedica-se a aprimorar fundamentos teóricos a partir da revisão/reconstrução de conceitos, ideias e ideologias, polêmicas, entre outros. Segundo Demo (1994), “[...] o conhecimento teórico adequado acarreta rigor conceitual, análise acurada, desempenho lógico, argumentação diversificada, capacidade explicativa” (p. 36). Além disso, tal tipo de pesquisa não se esgota em si mesma, mas sim busca por condições básicas para intervenção, a partir do pressuposto de que o conhecimento é a base concreta para uma intervenção adequada.

\section{DisCUTINDO O CONCEITO DE ESPORTE E JOGOS ESPORTIVOS}

O próprio conceito de esporte não é universal ou consensual na literatura, mas é possível se identificar duas proeminências interpretativas, uma em sentido mais lato e outra em sentido mais estrito (Tubino, 1987; Hartmann-Tews, 2015; Programa das Nações Unidas para o Desenvolvimento, 2017; Canan e Starepravo, 2019). O sentido mais lato é compartilhado, por exemplo, pela Carta Europeia do Esporte (Revisada) (Council of Europe, 2001), que compreende o esporte enquanto qualquer tipo de atividade física ou prática corporal sistematizada. O sentido estrito, por sua vez, é defendido exponencialmente por Parlebas (2001), que entende o esporte somente enquanto situações motrizes competitivas, regradas e institucionalizadas.

O elemento "situação motriz", como coloca Hernández Moreno (2000), deve ser parte insubstituível da prática. Em outros termos, a demanda motriz, ainda que não necessariamente implique em uma depleção 
energética considerável, deve ser um dos elementos essenciais para a conquista do êxito. É o caso, por exemplo, dos e-esportes, cuja ação motora de manuseio dos controles é condição indispensável para obtenção do êxito, não podendo ser delegada a terceiros. Diferentemente ocorre em relação aos jogos de tabuleiro ou de cartas, por exemplo, nos quais é possível que um terceiro manipule as peças/cartas com orientação do jogador, sem que isso comprometa seu desempenho. Isto resulta, em consequência, a exclusão de atividades exclusivamente determinadas pelo caráter intelectual do conceito de esporte, mesmo que algumas delas sejam disputadas sob uma lógica de competição institucionalizada. A institucionalização, por sua vez, significa que as práticas são organizadas por instituições dirigentes que padronizam as regras para que pessoas de diferentes regióes do globo possam competir entre si. Embora em uma primeira assertiva, a ideia de institucionalização remeta ao sistema federado internacional, o qual ainda é predominante, na atualidade já encontra-se também sob outras formas, sobretudo quando se trata de modalidades esportivas mais recentemente criadas e/ou difundidas. É o caso de modalidades regidas por federações nacionais ou continentais, que ainda não atingiram o patamar internacional (no sentido de abrangência intercontinental ou quase-mundial), ou modalidades regidas por associações (nacionais, regionais ou internacionais), mas que não assumiram, por qualquer razão que seja, ao caráter de federações, ou mesmo o caso das empresas ou franquias, ou seja, modalidades esportivas desenvolvidas por determinada instituição empresarial, que as oferecem enquanto produto de mercado, vendendo o know-how e os equipamentos/materiais oficiais para prática.

Ressalva-se que, em qualquer dos casos, é necessária a existência de um corpo de regras padronizado, mas o caráter de institucionalização diz respeito à prática e competição oficial, o que não impede a prática informal e/ou adaptada, desde que esta mantenha as regras primárias ou funcionais da modalidade esportiva (Almond, 1986a; Canan e Starepravo, 2019) (caso contrário, deixa de se caracterizar como determinada modalidade esportiva e, consequentemente, como esporte).

Considerando o conceito lato de esporte como demasiadamente abrangente, o que, como defende Parlebas (2001), o leva a perder seu caráter diferenciador em relação a outras práticas corporais, neste texto assumese o entendimento de esporte em sentido estrito, esclarecendo-se desde logo que, sob tal lógica, não existem diferentes esportes, mas sim diferentes modalidades esportivas. Cada uma apresenta um corpo especifico de regras, sobretudo primárias ou funcionais, que, por sua vez, determina a sua lógica interna ou dinâmica funcional, isto é, suas características peculiares de acontecimentos e as ações dos praticantes, que permitem identificar a modalidade enquanto tal.

Dentro do conjunto total de modalidades esportivas, encontra-se um subgrupo reconhecido como de jogos esportivos, muito embora não se tenha muita clareza sobre o que efetivamente sejam e quais modalidades abranjam. Bayer (1994) oferece uma primeira pista para se pensar a respeito, quando busca conceituar o que denomina de jogos esportivos coletivos, que apresentam elementos indispensáveis, chamados pelo autor de constantes ou denominadores comuns: bola, terreno, um alvo/meta para atacar e outro para defender, companheiros, adversários, e regras.

A simples transposição destes elementos aos jogos esportivos como um todo, retirando-se apenas os companheiros não é suficiente. Veja-se: os elementos regras e adversários encontram-se dentro do próprio conceito de esporte e, portanto, são presumidos dentro do conceito de jogos esportivos. O elemento alvo/ meta para atacar e defender não se mostra transferível para os jogos esportivos em geral e precisa ser revisto, inclusive, em relação aos jogos esportivos coletivos, pois muitos apresentam outros critérios de pontuação (por exemplo, beisebol e kin-ball, no caso dos coletivos e golfe ou squash no caso dos individuais).

Disto resulta que, dentre os constantes apresentados por Bayer (1994), somente os elementos bola e terreno aplicam-se invariavelmente a todo o conjunto de jogos esportivos, sendo que o terreno aplica-se também à maioria de modalidades esportivas em geral (exceto aquelas praticadas em um ambiente natural não delimitado a priori). Concordando-se com Ramírez Torrealba (2013), assim, que a bola ou qualquer objeto que o valha, doravante denominado móbil (disco, peteca, etc.) apresenta-se como o único elemento diferenciador entre os jogos esportivos e as modalidades esportivas em geral. 
Porém, também não é a simples presença do móbil que caracteriza os jogos esportivos, mas sim seu papel de principal elemento intermediador para definição de uma pontuação e, consequentemente, da vitória ou derrota. Isto exclui modalidades esportivas que, apesar de se utilizarem de um móbil, tem a definição de vitória ou derrota determinada por outros critérios, como a Ginástica Rítmica ou os arremessos e lançamentos do atletismo, por exemplo. No primeiro caso, é a performance técnica e estética, julgada por árbitros, que mais importa, e não a conquista de um objetivo específico por via do próprio móbil, ainda que a qualidade de sua manipulação seja também um fator interveniente para definição de vitória ou derrota. No segundo caso, não é o móbil que determina a pontuação, mas sim, a distância a qual ele é lançado/arremessado, respeitando uma quantidade pré-determinada de lançamentos/arremessos. Não de pontua mais, ou menos que adversário, mas sim se lança/arremessa o móbil mais longe, sendo a pontuação invariável em relação à qualidade dos lançamentos/arremessos.

Dessa forma, tratar de jogos esportivos significa, na realidade, tratar de jogos esportivos de móbil ou, popularmente, de jogos esportivos de bola. Um segundo elemento que contribui para identificação deste subgrupo de modalidades esportivas, também concordando-se com Ramírez Torrealba (2013), encontra-se no uso do verbo jogar. Não se fala em jogar ginástica ou atletismo, mas se fala em jogar basquetebol, futebol, tênis ou golfe. Possivelmente a adoção deste verbo para referir-se à prática de tais modalidades encontrese em seu caráter mais lúdico (brincar com a bola) que o existente em outros grupos de modalidades. Esse entendimento é compartilhado por Bayer (1994), quando afirma que o aspecto lúdico é inerente aos jogos esportivos coletivos, exemplificando-o também a partir do uso do verbo jogar (futebol, basquetebol, etc.).

Um terceiro elemento caracteriza a maioria dos jogos esportivos, mas não todos. Trata-se da interação entre os adversários, que significa que a ação de um interfere diretamente na do outro. Tendo em conta essa interação, os jogadores têm liberdade de escolha de suas ações, em resposta às situações do jogo. Isso é diferente de modalidades esportivas em que as ações são estereotipadas e invariáveis. Basta fazer uma simples comparação entre um a prova de corrida no atletismo e um jogo de futebol. Na corrida, nem mesmo é necessário que os competidores disputem simultaneamente, pois o que importa é o tempo utilizado por cada qual para percorrer o percurso. No jogo de futebol, os gols, que definirão vitória ou derrota, são fruto das interações entre os adversários, sendo impossível a prática sem a presença simultânea de ambas as equipes. As exceções encontram-se em alguns jogos esportivos meramente de precisão, em que os competidores disputam independentemente dos adversários, como é o caso do golfe ou do boliche, por exemplo.

Os jogos esportivos, assim, são aqui compreendidos como situações motrizes competitivas, regradas e institucionalizadas, praticadas em determinado território, sob a perspectiva de jogar com/contra outros, cuja pontuação e, consequentemente, vitória ou derrota, é definida por um elemento intermediário denominado móbil, e que, na maioria dos casos, demandam interação entre adversários. Assim como os jogos esportivos representam um subgrupo dentre as modalidades esportivas em geral, eles podem também ser subdivididos em categorias ainda menores.

\section{ClassificaÇões de Jogos esportivos}

Parlebas (2001) apresenta um sistema de classificação do que denomina situações motrizes, não restringindose aos jogos esportivos. Para tal, leva em conta a categoria incerteza ou imprevisibilidade, que pode ser gerada pelo próprio meio ambiente ${ }^{4}$, pelas interações com companheiros (comunicação motriz) e/ou pelas interações com adversários (contracomunicação motriz). Os jogos esportivos individuais inserem-se na categoria de situações sociomotrizes ${ }^{5}$ em que há incertezas geradas pelos adversários, mas não pelo meio ou por companheiros (tênis, por exemplo), ou na categoria de situações psicomotrizes em que não há incertezas de qualquer natureza (golfe, por exemplo). Os jogos esportivos coletivos, por sua vez enquadramse na categoria de situações sociomotrizes com incertezas geradas pelos adversários e companheiros, mas não pelo meio (futebol, por exemplo). 
A classificação apresentada por Parlebas (2001), contudo, mostra-se bastante abrangente, apresentando critérios gerais de categorização, mas não específicos, agrupando modalidades com lógicas internas bastante distintas. Basta se pensar no caso de futebol, voleibol e beisebol, por exemplo, todos jogos esportivos de cooperação e oposição, segundo a classificação do autor.

Nesta senda é que se insere a classificação apresentada por Hernández Moreno (2005), que, ao critério incerteza que pauta a classificação de Parlebas (2001), acrescenta os subcritérios uso do espaço (comum ou separado) e forma de participação (simultânea ou alternada) dos participantes. Nessa lógica, por exemplo, futebol, que é um jogo esportivo de cooperação e oposição disputado em campo comum e com participação simultânea dos jogadores (ambas as equipes podem intervir sobre a bola na maioria dos momentos do jogo), deixa de enquadrar-se na mesma categoria do voleibol, que também é um jogo esportivo de cooperação e oposição, mas disputado em espaço separado e com participação alternada dos jogadores (uma equipe só pode intervir sobre a bola quando outra finaliza sua ação ofensiva).

A classificação de Hernández Moreno (2005), contudo, embora mais específica que a de Parlebas (2001), ainda se mostra bastante abrangente, elencando dentro de uma mesma categoria, modalidades muito distintas, tais como o beisebol e o voleibol, por exemplo.

A classificação apresentada por Almond (1986b) é específica para os jogos esportivos e leva em conta suas dinâmicas funcionais, categorizando-os prioritariamente conforme as semelhanças de suas lógicas internas ou, nos termos utilizados pelo autor, dos problemas a serem resolvidos pelos jogadores ao longo do jogo, e secundariamente conforme aspectos técnico/motores. Não há, portanto, critérios específicos preconcebidos, mas sim uma divisão pautada na identificação de semelhanças funcionais, dividindo em jogos de invasão (com mão; com pés; com taco; com alvo centrado; com alvo de extremidades abertas); rede e parede (rede e raquete; rede e mão; e parede); campo e pontuação por corridas; e alvo.

O próprio Almond (1986b) cita uma categorização equivalente ${ }^{6}$ à sua própria, mas com algumas subdivisões distintas, apresentada por Ellis (citada em Almond, 1986b), que divide: jogos de território (equivalentes aos jogos de invasão) entre jogos de meta (futebol, basquetebol, etc.) e linha (rúgbi, futebol americano, etc.); jogos de quadra (equivalentes aos jogos de rede e parede) entre quadra dividida (badminton, tênis, etc.) e quadra compartilhada (squash, raquetebol, etc.); jogos de campo (equivalentes aos jogos de campo e pontuação por corridas) entre formato disperso (beisebol, softbol, etc.) e formato oval (críquete, stoolball); e jogos de alvo com oposição (bocha, croquete, etc.) e sem oposição (boliche, golfe). Ambas as classificações também não são isentas de problemas. Por buscarem ser mais específicas, acabam gerando categorias mais fechadas, como será discutido a partir do Quadro 1.

González (2006) e González e Bracht (2012) apresentam classificações praticamente idênticas, das modalidades esportivas em geral e, dentro delas, dos jogos esportivos em específico. Partem inicialmente do critério interação (e incertezas geradas) entre adversários e subsidiariamente de subcritérios pautados na lógica funcional das diferentes modalidades. Nessa esteira, apresentam, dentro do grupo de modalidades esportivas sem interação entre os adversários:

- De marca (González, 2006; González e Bracht, 2012): resultado definido pela comparação entre os índices alcançados pelos praticantes, em segundos, metros ou quilos.

- Estéticas (González, 2006) ou técnico-combinatórias (González e Bracht, 2012): resultado definido pela beleza plástica (dimensão estética) e grau de dificuldade (dimensão técnica ou acrobática) dos movimentos, respeitando critérios preestabelecidos.

- De precisão (González, 2006; González e Bracht, 2012): resultado definido pela aproximação ou acerto do móbil em alvo(s).

Em relação ao grupo de modalidades esportivas com interação entre os adversários, os autores apresentam: 
- De combate (González, 2006; González e Bracht, 2012) ou luta (González, 2006): resultado definido pela subjugação e/ou aplicação de golpes (toques, desequilíbrios, imobilizações, empurrões, etc.) sobre o adversário.

- De campo e taco (González, 2006; González e Bracht, 2012): objetiva-se rebater a bola para tentar percorrer a maior quantidade de bases ou distância entre as bases, a fim de somar pontos.

- Com rede/quadra dividida ou muro (González, 2006) ou com rede divisória ou parede de rebote (González e Bracht, 2012): objetivo de lançar o móbil em locais em que o adversário não o alcance ou de forma a forçar que cometa um erro.

- De invasão (González, 2006; González e Bracht, 2012) ou territoriais (González, 2006): objetivo de tentar ocupar a meia quadra ou campo do adversário para marcar pontos, além de defender sua própria meta.

Percebe-se que a única diferença entre as duas classificações encontra-se na nomenclatura de algumas categorias. Além de apresentarem os mesmos problemas de especificidade existentes na classificação de Almond (1986b) e Ellis (citada em Almond, 1986b), que podem excluir alguns jogos de características funcionais peculiares, desconsideram que alguns jogos de alvo, tais como a bocha ou o curling, por exemplo, apresentam interação com o adversário.

\section{ANÁLISE E REVISÃo DAS CLASSIFICAÇÕES DOS JOGOS ESPORTIVOS}

Esclarece-se que não está, aqui, se desconsiderando o mérito de qualquer uma das classificações analisadas e tampouco deixando-se de levar em conta que qualquer categorização demanda generalidade, sendo a especificidade de cada jogo esportivo identificada somente quando de sua análise individual. O que se propóe é tão somente, em linhas gerais, um exercício de revisão das diferentes classificações a fim de se identificar como elas se relacionam ou não com a quantidade e diversidade cada vez maior de jogos esportivos que surgem e se difundem a cada dia.

Os jogos esportivos peculiares, alguns já bem consolidados institucionalmente e outros em fase de institucionalização, selecionados como exemplos para nortear a discussão, são apresentados, brevemente explicados e relacionados às classificações supra-apresentadas, no Quadro 1. 
QUADRO 1

Jogos esportivos peculiares e sua relação com classificações existentes.

\begin{tabular}{|c|c|c|c|c|c|c|c|}
\hline $\begin{array}{l}\text { Jogo } \\
\text { esportivo }\end{array}$ & $\begin{array}{l}\text { Explicação } \\
\text { geral }\end{array}$ & $\begin{array}{l}\text { Parlebas } \\
\text { (2001) }\end{array}$ & $\begin{array}{l}\text { Hernánde } \\
\text { z Moreno } \\
(2005)\end{array}$ & $\begin{array}{l}\text { Almond } \\
\text { (1986b) }\end{array}$ & $\begin{array}{l}\text { Ellis } \\
\text { (citada em } \\
\text { Almond, } \\
1986 b \text { ) }\end{array}$ & $\begin{array}{l}\text { González } \\
(2006)\end{array}$ & $\begin{array}{l}\text { González } \\
\text { e Bracht } \\
(2012)\end{array}$ \\
\hline Baseball & $\begin{array}{l}\text { Após uma } \\
\text { rebatida, a } \\
\text { equipe deve } \\
\text { correr por } \\
\text { bases para } \\
\text { pontuar, } \\
\text { enquanto a } \\
\text { outra equipe } \\
\text { busca a bola } \\
\text { e tenta } \\
\text { chegar antes } \\
\text { com ela às } \\
\text { mesmas } \\
\text { bases. }\end{array}$ & $\begin{array}{l}\text { Situação } \\
\text { motriz } \\
\text { de } \\
\text { coopera } \\
\text { ção e } \\
\text { oposiçã } \\
\text { o }\end{array}$ & $\begin{array}{l}\text { Não se } \\
\text { enquadra } \\
\text { perfeitam } \\
\text { ente }\end{array}$ & $\begin{array}{l}\text { Jogo de } \\
\text { campo e } \\
\text { pontuação } \\
\text { por } \\
\text { corridas }\end{array}$ & $\begin{array}{l}\text { Jogo de } \\
\text { campo } \\
\text { com } \\
\text { formato } \\
\text { disperso }\end{array}$ & $\begin{array}{l}\text { Jogo de } \\
\text { campo e } \\
\text { taco }\end{array}$ & $\begin{array}{l}\text { Jogo de } \\
\text { campo e } \\
\text { taco }\end{array}$ \\
\hline $\begin{array}{l}\text { Over the } \\
\text { line }\end{array}$ & $\begin{array}{l}\text { Uma equipe } \\
\text { rebate a bola } \\
\text { para dentro } \\
\text { de uma área } \\
\text { específica e } \\
\text { a outra } \\
\text { equipe tenta } \\
\text { segurar a } \\
\text { bola antes } \\
\text { que toque no } \\
\text { solo. }\end{array}$ & $\begin{array}{l}\text { Situação } \\
\text { motriz } \\
\text { de } \\
\text { coopera } \\
\text { ção e } \\
\text { oposiçã } \\
\text { o }\end{array}$ & $\begin{array}{l}\text { Situação } \\
\text { motriz de } \\
\text { cooperaçã } \\
0 \quad \text { e } \\
\text { oposição, } \\
\text { em espaço } \\
\text { separado } \\
\text { e } \\
\text { participaç } \\
\text { ão } \\
\text { alternada }\end{array}$ & $\begin{array}{l}\text { Não se } \\
\text { enquadra } \\
\text { perfeitam } \\
\text { ente }\end{array}$ & $\begin{array}{l}\text { Não se } \\
\text { enquadra } \\
\text { perfeitame } \\
\text { nte. }\end{array}$ & $\begin{array}{l}\text { Não se } \\
\text { enquadra } \\
\text { perfeitame } \\
\text { nte. }\end{array}$ & $\begin{array}{l}\text { Não se } \\
\text { enquadra } \\
\text { perfeitame } \\
\text { nte. }\end{array}$ \\
\hline $\begin{array}{l}\text { Dodgebal } \\
l\end{array}$ & $\begin{array}{l}\text { Duas } \\
\text { equipes, } \\
\text { cada qual } \\
\text { em sua } \\
\text { quadra, }\end{array}$ & $\begin{array}{l}\text { Situação } \\
\text { motriz } \\
\text { de } \\
\text { coopera } \\
\text { ção e }\end{array}$ & $\begin{array}{l}\text { Não se } \\
\text { enquadra } \\
\text { perfeitam } \\
\text { ente }\end{array}$ & $\begin{array}{l}\text { Não se } \\
\text { enquadra }\end{array}$ & $\begin{array}{l}\text { Não se } \\
\text { enquadra } \\
\text { perfeitame } \\
\text { nte }\end{array}$ & $\begin{array}{l}\text { Não se } \\
\text { enquadra } \\
\text { perfeitame } \\
\text { nte }\end{array}$ & $\begin{array}{l}\text { Não se } \\
\text { enquadra }\end{array}$ \\
\hline
\end{tabular}




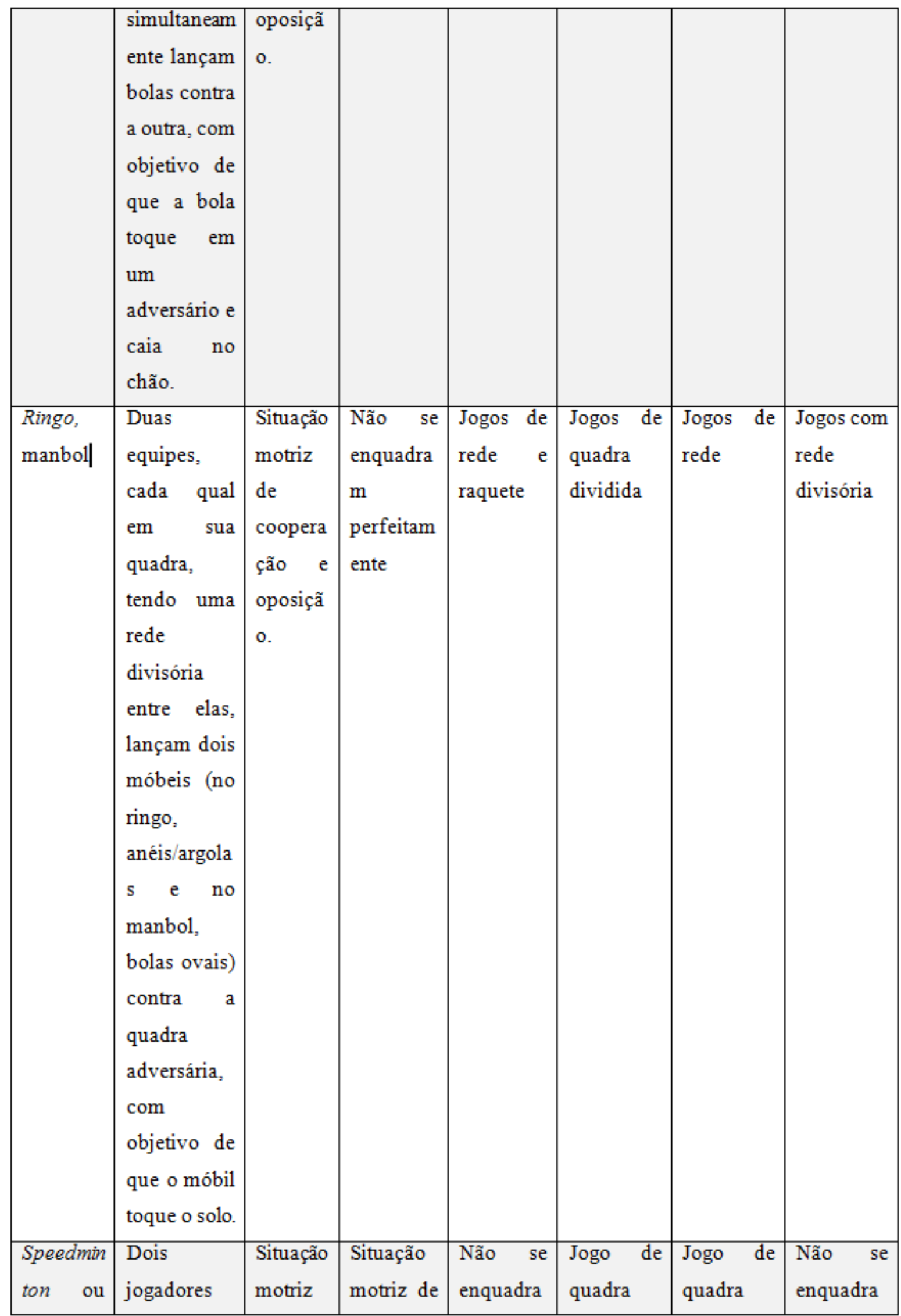




\begin{tabular}{|c|c|c|c|c|c|c|c|}
\hline $\begin{array}{l}\text { crossmint } \\
\text { on }\end{array}$ & $\begin{array}{l}\text { (ou duplas), } \\
\text { cada qual } \\
\text { em sua } \\
\text { quadra, e } \\
\text { com um } \\
\text { espaço } \\
\text { neutro entre } \\
\text { eles (sem } \\
\text { rede } \\
\text { divisória) } \\
\text { raqueteiam } \\
\text { uma peteca } \\
\text { contra a } \\
\text { quadra do } \\
\text { adversário, } \\
\text { com } \\
\text { objetivo de } \\
\text { que toque o } \\
\text { solo. }\end{array}$ & $\begin{array}{l}\text { de } \\
\text { oposiçã } \\
\text { o (jogo } \\
\text { individu } \\
\text { al) ou } \\
\text { de } \\
\text { coopera } \\
\text { ção e } \\
\text { oposiçã } \\
\text { o (jogo } \\
\text { em } \\
\text { duplas) }\end{array}$ & $\begin{array}{l}\text { oposição } \\
\text { (jogo } \\
\text { individual } \\
\text { ) ou de } \\
\text { cooperaçã } \\
\text { o e } \\
\text { oposição } \\
\text { (jogo em } \\
\text { duplas), } \\
\text { em espaço } \\
\text { separado } \\
\text { e } \\
\text { participaç } \\
\text { ão } \\
\text { alternada }\end{array}$ & & dividida & dividida & \\
\hline Speedball & $\begin{array}{l}\text { Dois } \\
\text { jogadores } \\
\text { (ou duplas), } \\
\text { cada qual } \\
\text { em sua } \\
\text { quadra, } \\
\text { devem } \\
\text { raquetear } \\
\text { uma bola } \\
\text { presa por } \\
\text { uma corda a } \\
\text { um mastro } \\
\text { central, com } \\
\text { objetivo de } \\
\text { que o outro } \\
\text { não consiga } \\
\text { raquetear }\end{array}$ & $\begin{array}{l}\text { Situação } \\
\text { motriz } \\
\text { de } \\
\text { oposiçã } \\
\text { o (jogo } \\
\text { individu } \\
\text { al) ou } \\
\text { de } \\
\text { coopera } \\
\text { ção e } \\
\text { oposiçã } \\
\text { o (jogo } \\
\text { em } \\
\text { duplas) }\end{array}$ & $\begin{array}{l}\text { Situação } \\
\text { motriz de } \\
\text { oposição } \\
\text { (jogo } \\
\text { individual } \\
\text { ) ou de } \\
\text { cooperaçã } \\
\text { o e } \\
\text { oposição } \\
\text { (jogo em } \\
\text { duplas), } \\
\text { em espaço } \\
\text { separado } \\
\text { e } \\
\text { participaç } \\
\text { ão } \\
\text { alternada }\end{array}$ & $\begin{array}{l}\text { Não se } \\
\text { enquadra }\end{array}$ & $\begin{array}{l}\text { Não se } \\
\text { enquadra } \\
\text { perfeitame } \\
\text { nte }\end{array}$ & $\begin{array}{l}\text { Não se } \\
\text { enquadra } \\
\text { perfeitame } \\
\text { nte }\end{array}$ & $\begin{array}{l}\text { Não se } \\
\text { enquadra }\end{array}$ \\
\hline
\end{tabular}




\begin{tabular}{|c|c|c|c|c|c|c|c|}
\hline & $\begin{array}{l}\text { antes que a } \\
\text { bola } \\
\text { complete } \\
\text { duas votas } \\
\text { sobre o } \\
\text { mastro. }\end{array}$ & & & & & & \\
\hline Frescobol & $\begin{array}{l}\text { Dois } \\
\text { jogadores, } \\
\text { com } \\
\text { raquetes, } \\
\text { trocam } \\
\text { passes em } \\
\text { quantidade } \\
\text { e/ou } \\
\text { qualidade } \\
\text { durante } \\
\text { determinado } \\
\text { tempo. Não } \\
\text { há oposição } \\
\text { e a } \\
\text { pontuação é } \\
\text { determinada } \\
\text { por juízes. }\end{array}$ & $\begin{array}{l}\text { Situação } \\
\text { motriz } \\
\text { de } \\
\text { coopera } \\
\text { ção }\end{array}$ & $\begin{array}{l}\text { Situação } \\
\text { motriz de } \\
\text { cooperaçã } \\
0 \quad \text { em } \\
\text { espaço } \\
\text { separado } \\
\text { e } \\
\text { participaç } \\
\text { ão } \\
\text { alternada }\end{array}$ & $\begin{array}{l}\text { Não se } \\
\text { enquadra }\end{array}$ & $\begin{array}{l}\text { Não se } \\
\text { enquadra } \\
\text { perfeitame } \\
\text { nte }\end{array}$ & $\begin{array}{l}\text { Não se } \\
\text { enquadra } \\
\text { perfeitame } \\
\text { nte }\end{array}$ & $\begin{array}{l}\text { Não se } \\
\text { enquadra }\end{array}$ \\
\hline Kronum & $\begin{array}{l}\text { Duas } \\
\text { equipes, em } \\
\text { espaço } \\
\text { comum, } \\
\text { manipuland } \\
\text { o a bola com } \\
\text { as mãos ou } \\
\text { pés, têm o } \\
\text { objetivo de } \\
\text { lançar ou } \\
\text { chutar a bola } \\
\text { contra uma } \\
\text { das quatro }\end{array}$ & $\begin{array}{l}\text { Situação } \\
\text { motriz } \\
\text { de } \\
\text { coopera } \\
\text { ção e } \\
\text { oposiçã } \\
\text { o }\end{array}$ & $\begin{array}{l}\text { Situação } \\
\text { motriz de } \\
\text { cooperaçã } \\
\text { o e } \\
\text { oposição, } \\
\text { em espaço } \\
\text { comum e } \\
\text { participaç } \\
\text { ão } \\
\text { simultâne } \\
\text { a }\end{array}$ & $\begin{array}{l}\text { Não se } \\
\text { enquadra }\end{array}$ & $\begin{array}{l}\text { Não se } \\
\text { enquadra }\end{array}$ & $\begin{array}{l}\text { Não se } \\
\text { enquadra }\end{array}$ & $\begin{array}{l}\text { Não se } \\
\text { enquadra }\end{array}$ \\
\hline
\end{tabular}




\begin{tabular}{|c|c|c|c|c|c|c|c|}
\hline & $\begin{array}{l}\text { metas ou } \\
\text { cestas. A } \\
\text { equipe pode } \\
\text { atacar em } \\
\text { qualquer um } \\
\text { dos alvos e } \\
\text { uma equipe } \\
\text { pode roubar } \\
\text { a bola da } \\
\text { outra. }\end{array}$ & & & & & & \\
\hline $\begin{array}{l}\text { Basketbal } \\
l 3 \times 3\end{array}$ & $\begin{array}{l}\text { Duas } \\
\text { equipes, } \\
\text { manipuland } \\
\text { o a bola com } \\
\text { as mãos, } \\
\text { atacam uma } \\
\text { única cesta. } \\
\text { Sempre que } \\
\text { a posse de } \\
\text { bola muda } \\
\text { de equipe, } \\
\text { ela deve sair } \\
\text { de uma área } \\
\text { distante da } \\
\text { cesta antes } \\
\text { de iniciar } \\
\text { um ataque à } \\
\text { mesma. } \\
\text { Uma equipe } \\
\text { pode roubar } \\
\text { a bola da } \\
\text { outra. }\end{array}$ & $\begin{array}{l}\text { Situação } \\
\text { motriz } \\
\text { de } \\
\text { coopera } \\
\text { ção e } \\
\text { oposiçã } \\
\text { o }\end{array}$ & $\begin{array}{l}\text { Situação } \\
\text { motriz de } \\
\text { cooperaçã } \\
0 \\
\text { oposição, } \\
\text { em espaço } \\
\text { comum e } \\
\text { participaç } \\
\text { ão } \\
\text { simultâne } \\
\text { a }\end{array}$ & $\begin{array}{l}\text { Não se } \\
\text { enquadra }\end{array}$ & $\begin{array}{l}\text { Não se } \\
\text { enquadra }\end{array}$ & $\begin{array}{l}\text { Não se } \\
\text { enquadra }\end{array}$ & $\begin{array}{l}\text { Não se } \\
\text { enquadra }\end{array}$ \\
\hline $\begin{array}{l}\text { Tchouckb } \\
\text { all }\end{array}$ & $\begin{array}{l}\text { Duas } \\
\text { equipes, em } \\
\text { espaço } \\
\text { comum têm }\end{array}$ & $\begin{array}{l}\text { Situação } \\
\text { motriz } \\
\text { de } \\
\text { coopera }\end{array}$ & $\begin{array}{l}\text { Situação } \\
\text { motriz de } \\
\text { cooperaçã } \\
0 \quad \mathrm{e}\end{array}$ & $\begin{array}{l}\text { Não se } \\
\text { enquadra }\end{array}$ & $\begin{array}{l}\text { Não se } \\
\text { enquadra } \\
\text { perfeitame } \\
\text { nte }\end{array}$ & $\begin{array}{l}\text { Não se } \\
\text { enquadra }\end{array}$ & $\begin{array}{l}\text { Não se } \\
\text { enquadra }\end{array}$ \\
\hline
\end{tabular}




\begin{tabular}{|c|c|c|c|c|c|c|c|}
\hline & $\begin{array}{l}\text { o objetivo } \\
\text { de lançar a } \\
\text { bola com as } \\
\text { mãos contra } \\
\text { um alvo } \\
\text { elástico } \\
\text { posicionado } \\
\text { em uma das } \\
\text { linhas de } \\
\text { fundo, com } \\
\text { objetivo de } \\
\text { que a bola } \\
\text { reboteada } \\
\text { toque o solo. } \\
\text { A equipe } \\
\text { pode atacar } \\
\text { em qualquer } \\
\text { um dos } \\
\text { alvos e uma } \\
\text { equipe não } \\
\text { pode roubar } \\
\text { a bola da } \\
\text { outra. }\end{array}$ & $\begin{array}{l}\text { ção e } \\
\text { oposiçãa } \\
0\end{array}$ & $\begin{array}{l}\text { oposição, } \\
\text { em espaço } \\
\text { comum e } \\
\text { participaç } \\
\text { ão } \\
\text { alternada }\end{array}$ & & & & \\
\hline Kin-ball & $\begin{array}{l}\text { Três } \\
\text { equipes, em } \\
\text { espaço } \\
\text { comum, têm } \\
\text { objetivo de } \\
\text { rebater com } \\
\text { as mãos uma } \\
\text { grande } \\
\text { leve bola } \\
\text { contra o } \\
\text { solo, sem } \\
\text { que uma das } \\
\text { equipes }\end{array}$ & $\begin{array}{l}\text { Situação } \\
\text { motriz } \\
\text { de } \\
\text { coopera } \\
\text { ção e } \\
\text { oposiçã } \\
\text { o }\end{array}$ & $\begin{array}{l}\text { Situação } \\
\text { motriz de } \\
\text { cooperaçã } \\
\text { o e } \\
\text { oposição, } \\
\text { em espaço } \\
\text { comum e } \\
\text { participaç } \\
\text { ão } \\
\text { altemada }\end{array}$ & $\begin{array}{l}\text { Não se } \\
\text { enquadra }\end{array}$ & $\begin{array}{l}\text { Não se } \\
\text { enquadra } \\
\text { perfeitame } \\
\text { nte }\end{array}$ & $\begin{array}{l}\text { Não se } \\
\text { enquadra }\end{array}$ & $\begin{array}{l}\text { Não se } \\
\text { enquadra }\end{array}$ \\
\hline
\end{tabular}




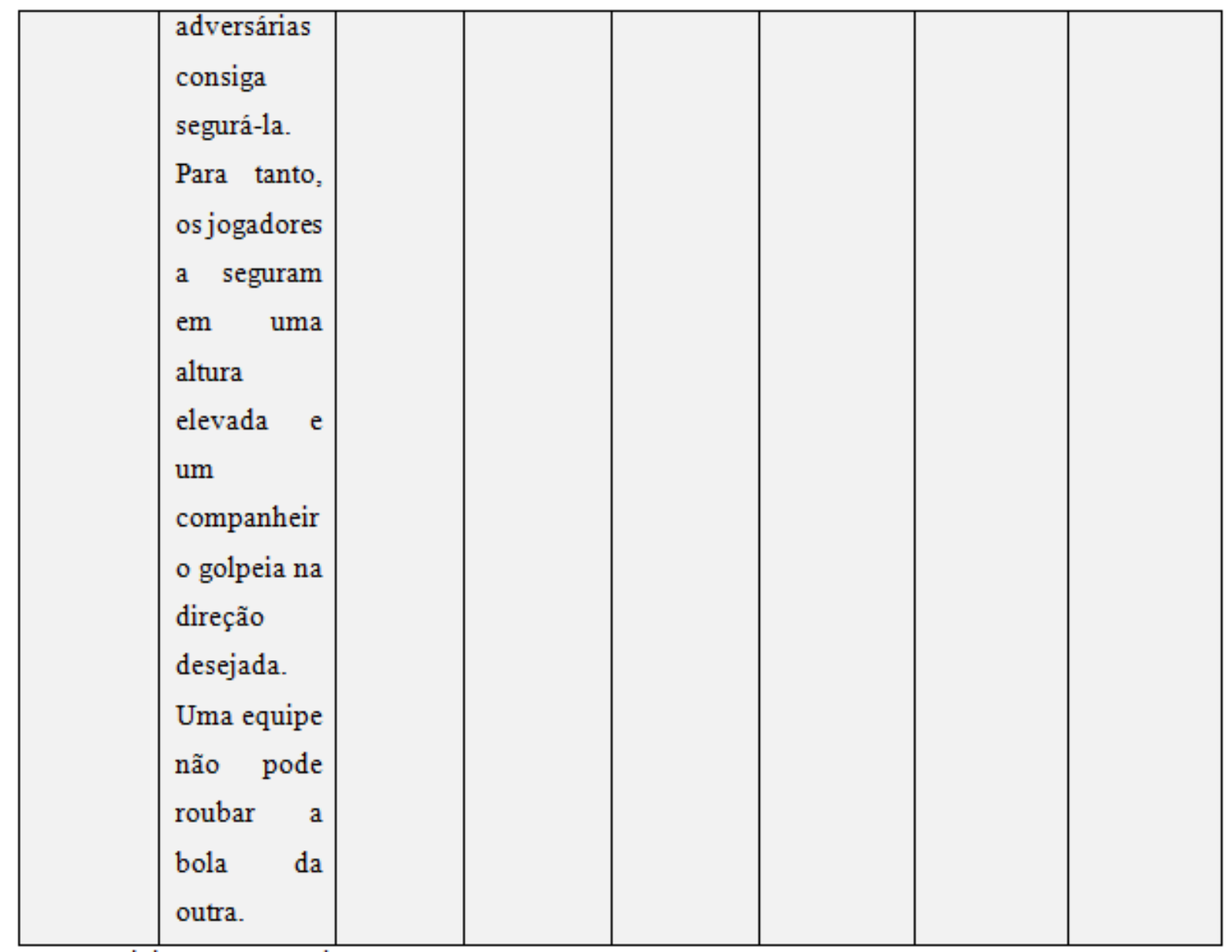

Fonte: elaboração própria.

Percebe-se pelo Quadro 1, que somente a categorização criada por Parlebas (2001) dá conta de englobar todos os jogos esportivos analisados. Entretanto, como já apontado, tal categorização mostra-se muito genérica e não permite a aproximação e distanciamento de jogos de acordo com sua lógica interna. Tomandose por base as demais classificações, que são mais específicas, tem-se que:

1. O Baseball, embora à primeira vista pudesse ser entendido como jogo de espaço separado e participação alternada, na realidade não enquadra-se perfeitamente na classificação de Henández Moreno (2005), pois, a partir de uma análise mais acurada, identifica-se que o espaço é um misto entre comum e separado (existe um único campo, mas com uma divisão organizacional de espaços) e a participação é um misto entre alternada e simultânea (existem momentos em que as equipes atuam simultaneamente, para disputa por certos espaços - bases). O Over the Line, por sua, vez, embora seja um jogo de rebatida, não se enquadra perfeitamente nas classificações de Almond (1986b), Ellis (citada em Almond, 1986b), González (2006) e González e Bracht (2012), pois a pontuação não ocorre por corridas e sim pela ineficácia da equipe adversária em apanhar a bola rebatida.

2. Dodgeball, Speedminton, Speedball e Frescobol não se enquadram nas classificações de Almond (1986b) e González e Bracht (2012) porque não apresentam a presença de rede ou parede frontal para troca de bola entre os adversários. Embora enquadrem-se na categoria de jogos de quadra dividida encontrada nas classificações de Ellis (citada em Almond, 1986b) e González (2006), apresentam características funcionais diferentes dos jogos exemplificados pelos autores (com exceção do Speedminton). 
3. Dodgeball, Ringo e Manbol não se enquadram perfeitamente na classificação de Hernández Moreno (2005), pois a participação pode ser interpretada como alternada (uma equipe não pode roubar o móbil da outra) ou simultânea (cada equipe com seus móbeis, realiza ações simultâneas à adversária).

4. Tchouckball, Kronum e Basketball 3x3 não se enquadram enquanto jogos de invasão [embora Almond (1986b) cite o Tchouckball como tal] porque são disputados em espaço comum onde não há um alvo para atacar e outro para defender. Também não se tratam de jogos de quadra compartilhada [como poderia se presumir a partir de Ellis (citada em Almond, 1986b)] porque, tomando-se por base os jogos exemplificados pela autora, tal categoria abrange somente jogos de participação alternada e parede frontal. O Tchouckball, ainda que seja disputado em quadra compartilhada e tenha participação alternada, não conta com parede frontal. O mesmo vale para o Kin-ball.

Percebe-se, assim, tomando-se por base somente os jogos exemplificados no Quadro 1, que muitos jogos esportivos, em razão de suas lógicas internas peculiares e amálgama de características de diferentes categorias, não enquadram-se em uma ou outra classificação, demonstrando que todas apresentam-se incompletas. A partir de tal constatação, buscou-se esboçar um aprimoramento das classificações apresentadas, conjugandoas naquilo que é possível, adequando sua nomenclatura para que possam abranger jogos esportivos até então não abrangidos e acrescentando categorias/subcategorias que contribuam para reunir jogos esportivos com características funcionais semelhantes.

Para tanto, recrutou-se também o critério trajetórias predominantes da bola citado (mas não conceituado) por Garganta (1998), que divide os jogos entre de troca de bola e de circulação de bola. O termo circulação, que remete à possibilidade de troca de passes entre os jogadores da equipe, foi aqui substituído por progressão, que pode dar-se tanto por meio de passes quanto por meio de condução do móbil.

Partindo-se, assim, primeiramente de critérios de aproximação e/ou da dinâmica funcional (problemas a serem resolvidos pelos jogadores) e secundariamente de aspectos técnico/motores adotados em cada classificação, mas não restringindo-se a eles, chegou-se ao esboço de um modelo que busca abranger as especificidades dos diferentes jogos esportivos conhecidos e reconhecidos até o presente momento, apresentado no Quadro 2. Esclarece-se que se denomina esboço justamente por não pretender-se que seja tratado enquanto uma categorização pronta, mas sim, tão somente de um passo inicial, um ponto de partida para se pensar em uma reclassificação dos jogos esportivos. 
QUADRO 2

Esboço de um modelo revisado de classificações de jogos esportivos ${ }^{7}$

\begin{tabular}{|c|c|c|c|}
\hline $\begin{array}{l}\text { Categor } \\
\text { ia } \\
\text { principa } \\
1\end{array}$ & $\begin{array}{l}\text { Categoria } \\
\text { secundária }\end{array}$ & Categoria terciária $^{8}$ & Exemplos de jogos abrangidos $^{9}$ \\
\hline $\begin{array}{l}\text { Jogos } \\
\text { com } \\
\text { interaçã } \\
\text { o entre } \\
\text { adversá } \\
\text { rios, de } \\
\text { territóri } \\
\text { o e } \\
\text { progres } \\
\text { são com } \\
\text { mópil }\end{array}$ & $\begin{array}{l}\text { Invasão } \mathrm{de} \\
\text { território }\end{array}$ & $\begin{array}{l}\text { Pontuação principal } \\
\text { por alvo ou meta }\end{array}$ & $\begin{array}{l}\text { Alvo/cesta: Basketball; Cestoball; } \\
\text { Combaton; Horseball; Korfball; Motoball; } \\
\text { Netball; Pato; Quidditch; Ringball; } \\
\text { Slamball; Underwater Rugby; Unicycle } \\
\text { Basketball; } \\
\text { Meta: Cycle Ball; Football [Australian; } \\
\text { Beach; Field (soccer); Futsal; Gaelic; } \\
\text { International Rules; Jorkyball; Roller } \\
\text { Soccer; Showbol; Society]; Handball } \\
\text { (Beach; Court); Hockey (Bandy; Grass; } \\
\text { Ice; Inline; Roller; Underwater; Shinty; } \\
\text { Floorball;Ringette; Street and Ball; Rink } \\
\text { Bandy; Unicycle); Lacrosse (Hurling; } \\
\text { Camogie; Intercrosse; Polocrosse); Polo } \\
\text { (Horse; Camel; Elephant, Yak; Bike; } \\
\text { Kayak; Aquatic; Segway); Roll Ball; } \\
\text { Tapembol; } \\
\text { Alvo/cesta e meta: Polibol }\end{array}$ \\
\hline & & $\begin{array}{l}\text { Pontuação principal } \\
\text { por chegada à } \\
\text { determinada área }\end{array}$ & $\begin{array}{l}\text { American Football (Arena ou Indoor; } \\
\text { Canadian; Flag); Rugby (Beach; League; } \\
\text { Sevens; Tag; Union); Ultimate (Beach; } \\
\text { Field). }\end{array}$ \\
\hline
\end{tabular}




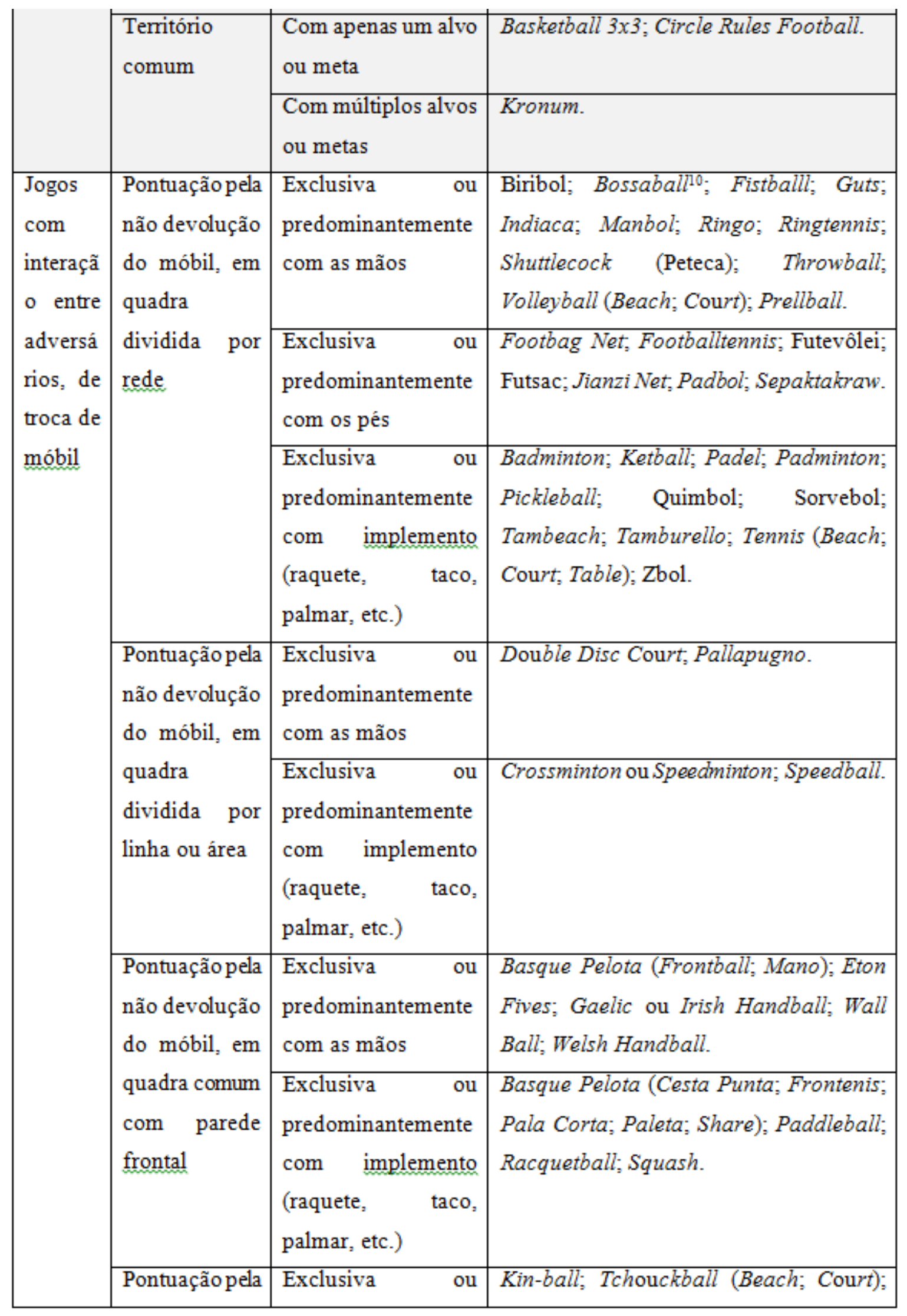




\begin{tabular}{|c|c|c|c|}
\hline & \multirow{2}{*}{$\begin{array}{l}\text { não devolução } \\
\text { do móbil, em } \\
\text { quadra comum } \\
\text { sem parede } \\
\text { frontal. }\end{array}$} & $\begin{array}{l}\text { predominantemente } \\
\text { com as mãos }\end{array}$ & Spikeball ou Roundnet. \\
\hline & & $\begin{array}{l}\text { Exclusiva ou } \\
\text { predominantemente } \\
\text { com implemento } \\
\text { (raquete, taco, } \\
\text { palmar, etc.) }\end{array}$ & 360 ball. \\
\hline & $\begin{array}{l}\text { Pontuação } \\
\text { pelo acerto da } \\
\text { bola no } \\
\text { adversário }\end{array}$ & - & Dodgeball. \\
\hline \multirow{3}{*}{$\begin{array}{l}\text { Jogos } \\
\text { com } \\
\text { interaçã } \\
\text { o entre } \\
\text { adversá } \\
\text { rios, de } \\
\text { rebatida } \\
\text { e } \\
\text { apanhad } \\
\text { ura do } \\
\text { móbil }\end{array}$} & $\begin{array}{l}\text { Pontuação por } \\
\text { corridas por } \\
\text { bases }\end{array}$ & - & $\begin{array}{l}\text { Baseball; Brännboll, British Baseball; } \\
\text { Kickball; Pesäpallo; Rounders; Softball. }\end{array}$ \\
\hline & $\begin{array}{l}\text { Pontuação por } \\
\text { corridas de ida } \\
\text { e volta }\end{array}$ & - & $\begin{array}{l}\text { Cricket, Lapta; Oină; Stoolbal; Tacobol; } \\
\text { Vigoro. }\end{array}$ \\
\hline & Sem corrida & - & Over the Line. \\
\hline \multirow{3}{*}{$\begin{array}{l}\text { Jogos } \\
\text { merame } \\
\text { nte de } \\
\text { precisão } \\
\text { ou alvo }\end{array}$} & \multirow[t]{2}{*}{$\begin{array}{l}\text { Com interação } \\
\text { entre os } \\
\text { adversários }\end{array}$} & $\begin{array}{l}\text { De campo, quadra ou } \\
\text { pista }\end{array}$ & $\begin{array}{l}\text { Bocce; Cornhole; Crocket, Curling; } \\
\text { Gateball; Ice Stock Sport, Lawn Bowling; } \\
\text { Malha; Petanque; Woodball (Beach; } \\
\text { Field). }\end{array}$ \\
\hline & & De mesa & $\begin{array}{l}\text { Billiards; Pool; Snooker; Sports Table } \\
\text { Football (Futebol de mesa ou botão); } \\
\text { Table Soccer (Pebolim) }{ }^{11} \text {. }\end{array}$ \\
\hline & Sem interação & De campo, quadra ou & Bowling; Dart, Disc Golf, Footbag Golf, \\
\hline
\end{tabular}




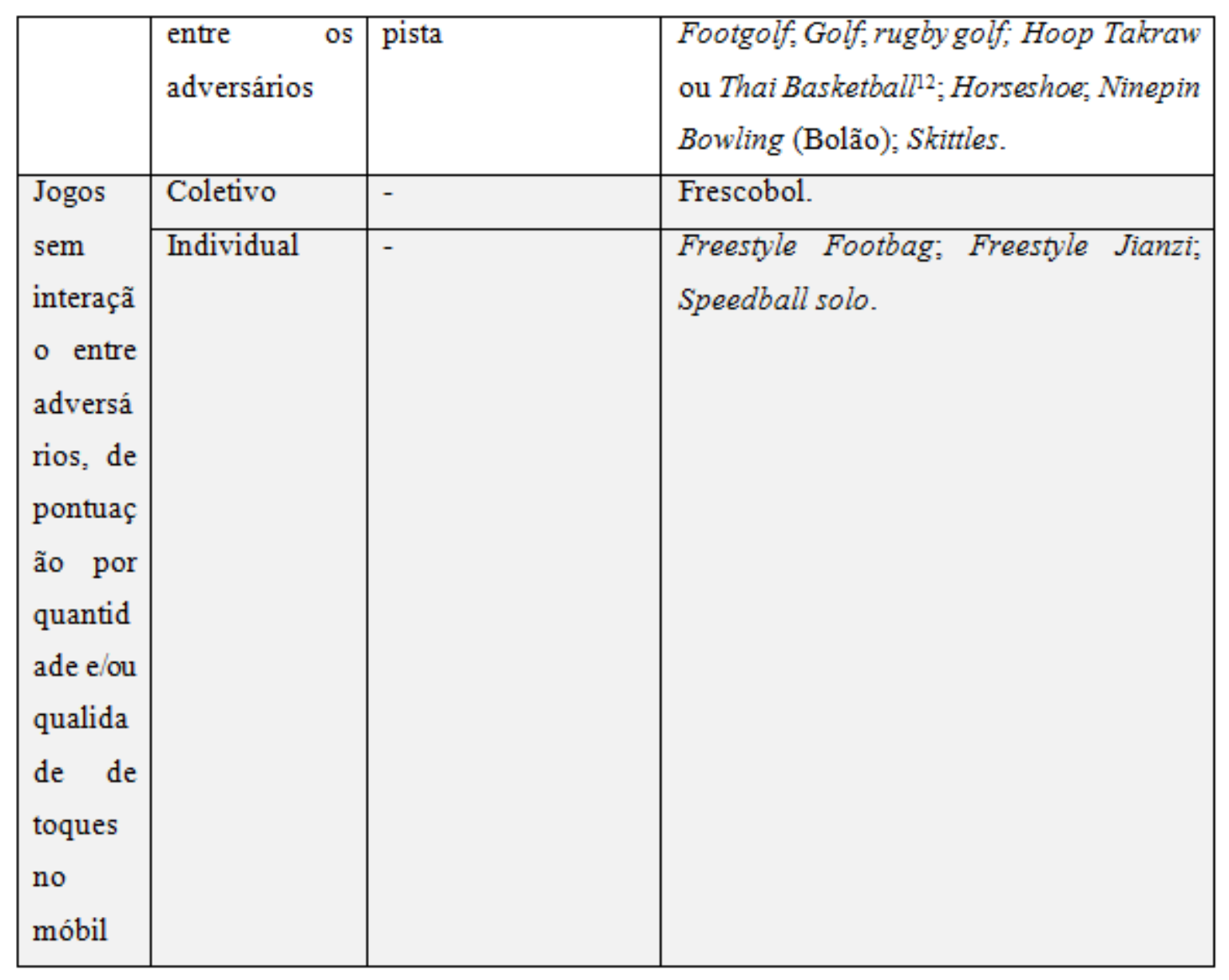

Fonte: elaboração própria.

Os jogos com interação entre adversários, de território e progressão com móbil (ou, simplificadamente, jogos de progressão com móbil) tratam-se daqueles em que a pontuação é definida pela chegada da equipe com móbil em determinada área ou pelo seu acerto em determinada meta/alvo, podendo os jogadores progredirem com posse do móbil em direção ao objetivo e sendo possível a intervenção simultânea do adversário (sobre o móbil). Podem ser disputados com cada equipe defendendo sua meia quadra/campo e podendo invadir a do adversário para se aproximar do objetivo, ou com ambas as equipes dividindo um território comum. No primeiro caso, existe um alvo ou área para atacar e outro para defender, ao passo que, no segundo caso, existe apenas um ou múltiplos alvos, com as equipes reordenando seu posicionamento de ataque e defesa de acordo com a posse de bola.

Os jogos com interação entre adversários, de troca de móbil (ou, simplificadamente, jogos de troca de móbil) são aqueles em que a dinâmica funcional consiste no lançamento do móbil para o adversário, mas buscando dificultar ao máximo sua respectiva ação ofensiva. Na maioria dos jogos desta categoria, a pontuação ocorre pela ineficácia do adversário em devolver o móbil para ele remetido (por não conseguir recepcioná-lo ou por não conseguir "re-remetê-lo" adequadamente), mas pode ocorrer também em decorrência de acertar o móbil no adversário sem que ele consiga apreendê-lo. A troca de móbil entre adversários pode se dar sobre uma rede, sobre uma linha ou área demarcada no chão, após seu contato com uma parede frontal ou após a realização de uma ação ofensiva específica (no caso dos jogos disputados em espaço comum e sem parede frontal).

Os jogos com interação entre adversários, de rebatida e apanhadura (ou, simplificadamente, jogos de rebatida) são aqueles em que uma equipe rebate o móbil e outra o apanha. A pontuação ocorre predominante, mas não exclusivamente pela maior quantidade de vezes em que a equipe percorre determinado trajeto após 
a rebatida do móbil, enquanto o adversário o apanha. Esta corrida pode se dar percorrendo um trajeto específico, comumente demarcado por bases, ou a partir de idas e voltas, nas quais o jogador pontua quando vai até a linha de fundo oposta e/ou quando volta da mesma.

Entretanto, existem casos em que a simples ineficácia de uma equipe em apanhar um móbil rebatido resulta em ponto para equipe rebatedora, ou casos em que o lançamento do móbil contra um jogador que está realizando uma corrida resulta em ponto para a equipe apanhadora. Outra diferença entre os jogos desta categoria é que a rebatida pode se dar a partir de um lançamento feito de longe por um adversário; de perto por um adversário; pela própria equipe; ou pelo próprio rebatedor.

Os jogos meramente de precisão ou alvo (ou, simplificadamente, jogos de alvo) são aqueles em que os jogadores buscam acertar ou aproximar o móbil de determinado alvo. O termo meramente não é utilizado para depreciar os jogos compreendidos nesta categoria, mas sim para diferenciá-lo de outras categorias, nas quais, em que pese possa-se também objetivar o acerto do móbil em um alvo, esta não é sua única característica. Os jogos meramente de precisão ou alvo podem ocorrer com interação entre os adversários, quando um jogador, por meio de seu(s) próprio(s) móbil(eis), pode deslocar o(s) móbil(eis) alheio(s), ou sem interação, quando cada jogador realiza suas ações sem qualquer interferência do adversário. Podem ser divididos também em relação ao terreno de jogo que poder ser quadra/campo/pista ou mesa.

Os jogos sem interação entre adversários, de pontuação por quantidade e/ou qualidade de toques no móbil (ou, simplificadamente, jogos de pontuação por toques no móbil) são aqueles em que os jogadores buscam realizar o máximo de toques no móbil dentro de determinado tempo e/ou buscam atingir a maior pontuação possível, atribuída por jurados, para movimentos técnicos/acrobáticos com o móbil. Não se tratam de jogos esportivos nos quais outros critérios e/ou elementos acrobáticos pontuam, como no caso da ginástica rítmica, mas sim, daqueles em que a pontuação é atribuída exclusivamente aos movimentos de habilidade realizados com o próprio móbil. Podem ser disputados individualmente ou em cooperação com companheiros.

Outra possibilidade de revisão das classificações já existentes seria a simples manutenção, em cada qual, das respectivas categorias, somando-se às mesmas uma nova categoria de caráter misto e/ou denominação de "outros", que agruparia os jogos esportivos com características peculiares e não abrangidos pelas categorias preexistentes. Embora esta opção mostre-se mais simples do que uma revisão mais completa das classificações já existentes, apresenta como problema o fato de que os jogos da categoria outros teriam lógicas muitos distintas. Consequentemente, a compreensão da lógica interna de cada jogo esportivo ali abrangido somente seria possível a partir da análise de cada qual individualmente.

\section{CONSIDERAÇÕES FINAIS}

Tomando como base de análise alguns jogos esportivos com características peculiares, identificou-se que diferentes classificações que buscam agrupá-los tendo em conta aspectos relativos às suas lógicas internas, não se mostram capazes de abranger todos os jogos existentes na atualidade. Somente a classificação de Parlebas (2001) mostra-se plenamente abrangente. Contudo, por ser bastante genérica e agrupar modalidades com dinâmicas funcionais e/ou problemas a serem resolvidos pelos jogadores bastante distintos, ela acaba servindo mais como um ponto de partida para classificações mais específicas.

Aos jogos esportivos tomados como exemplo para análise e discussão, poderia somar-se Pallapugno, Padel, Ketball, 360ball, Circle Rules Football, Quidditch, entre vários outros exemplos, cada qual que apresenta uma dinâmica peculiar que demanda um ajuste, como o esboçado, nas classificações preexistentes. Entendendo que existe uma diversidade crescente de jogos esportivos, o exercício de revisão de suas classificações, assim como de interpretação de seu conceito e do próprio conceito de esporte, e também de apresentação de um inventário de tais jogos não pretende-se definitivo, tratando-se tão somente de um passo inicial para fomentar, estimular e aprofundar discussões sobre a temática. 


\section{REFERÊNCIAS}

Almond, L. (1986a). Primary and secondary rules in games. In Thorpe, R., Bunker, D., and Almond, L. Rethinking games teaching (pp. 73-74.). Loughborough: Department of Physical Education and Sports Science. University of Technology.

Almond, L. (1986b). Reflecting on themes: a games classification. In Thorpe, R., Bunker, D., and Almond, L. Rethinking games teaching (pp. 71-72.). Loughborough: Department of Physical Education and Sports Science. University of Technology.

Bayer, C. (1994). O ensino dos desportos colectivos. Lisboa: Dinalivro.

Canan, F., e Starepravo, F. A. (2019). O significado e a abrangência do direito ao esporte a partir de documentos internacionais. Fair Play. Revista de Filosofia, Ética y Derecho del Deporte, 15, 1-36. Recuperado de https://rac o.cat/index.php/FairPlay/issue/view/27911/2

Council of Europe (2001). Recommendation No. R (92) 13 Rev - On the Revised European Sports Charter. Brussels: Committee of Ministers.

Demo, P. (1994). Pesquisa e construção do conhecimento: metodologia cientifica no caminho de Habermas. Rio de Janeiro: Tempo Brasileiro.

Demo, P. (2000). Metodologia do conhecimento cientifico. São Paulo: Atlas.

Garganta, J. (1998). Para uma teoria dos jogos desportivos colectivos. Em Graça, A., y Oliveira, J. (Ed.). O ensino dos jogos desportivos ( $3^{\mathrm{a}} \mathrm{ed}$.) (pp. 11-26). Lisboa: FCDEF.

González, F. J., e Bracht, V. (2012). Metodologia do ensino dos esportes coletivos. Vitória: UFES.

González, F. J, Darido, S. C., e Oliveira, A. A. B. (org.) (2017a). Esportes de marca e com rede divisória ou muro/parede de rebote: badminton, peteca, tênis de campo, tênis de mesa, voleibol, atletismo ( $2^{\mathrm{a}}$ ed.). Maringá: Eduem.

González, F. J, Darido, S. C., e Oliveira, A. A. B. (org.) (2017b). Esportes de invasão: basquetebol, futebol, futsal, handebol, ultimate frisbee ( $2^{a}$ ed.). Maringá: Eduem.

González, F.J., e Fraga, A. B. (2009). Educação Física. Em Secretaria Da Educação. Referencial Curricular - Lições do Rio Grande: Linguagens, Códigos e suas Tecnologias - Artes e Educação Física (pp. 111-181). Secretaria da Educação: Rio Grande do Sul.

González, F. J. (2006). Sistema de Classificação dos Esportes. Em Rezer, R. (Org.). O fenômeno esportivo: ensaios criticoreflexivos (111-121). Chapecó: Argos.

Hartmann-Tews, I. (2015). Estratificação social e políticas públicas de esporte na União Européia. Em Santos, E. S., e Leiro, A. C. R. (Org.). Politicas públicas de esporte e lazer: diálogos (151-172). Petrolina: UNIVASF.

Hernández Moreno, J. (2000). La inicición a los deportes desde su estructura u dinámica - aplicación a la educación fisica escolar y al entrenamiento deportivo. Barcelona: INDE.

Hernández Moreno, J. (2005). Fundamentos del deporte - análisis de las estructuras del juego deportivo (3a ed.). Barcelona: INDE.

Ministério da Educação (2017). Base Nacional Comum Curricular - Educação éa Base. Brasil: Ministério da Educação.

Parlebas, P. (2001). Juegos, deporte y sociedad - léxico de praxiologia motriz. Barcelona: Paidotribo.

Programa das Nações Unidas para o Desenvolvimento (2017). Relatório de Desenvolvimento Humano Nacional Movimento éVida: Atividades Físicas e Esportivas para Todas as Pessoas. Brasília: PNUD.

Ramírez Torrealba, J. (2013). Taxonomía de las disciplinas deportivas. Revista Electrónica Actividad Física y Ciencias, 5 (2), 1-24. Recuperado de http://revistas.upel.edu.ve/index.php/actividadfisicayciencias/article/viewFile/506 $6 / 2623$.

Tubino, M. J. G. (1987). Teoria geral do esporte. São Paulo: IBRASA. 


\section{Notas}

1 O sistema de classificação das situações motrizes vem sendo desenvolvido e apresentado por Parlebas desde a década de 1970.

2 A apresentação original da classificação, de autoria de Hernández Moreno em conjunto a Blázquez Sánchez é da década de 1980.

3 Ver, por exemplo, Hernández Moreno (2000), que apresenta vários conceitos de esporte, ou Hartmann-Tews (2015), o relatório do Programa das Nações Unidas para o Desenvolvimento (2017) e Canan e Starepravo (2019), que discutem os sentidos pelos quais o termo esporte vem sendo abrangido.

4 Dizem respeito às situações motrizes praticadas em ambientes naturais não estandardizados, isto é, não padronizados. É o caso, por exemplo, do rafting, iatismo ou montanhismo, Como as condições ambientais são variáveis, geram incertezas aos praticantes quanto à próxima ação ser executada, de forma que precisam desenvolver, para além de técnicas padronizadas, competências de adaptação.

5 Situações que exigem interações motrizes, ou seja, interações diretas (não obrigatoriamente contato físico) entre os jogadores, que geram incertezas quanto à ação subsequente de cada um deles (a ação de um obrigatoriamente exige uma reação do outro). São diferentes das situações psicomotrizes, em que não há interação entre os praticantes. Neste tipo de situação, por mais que os praticantes compitam entre si, cada um atua, em termos de relaçóes motrizes, independentemente de companheiros ou adversários, como acontece no atletismo (exceto corridas de revezamento) ou no halterofilismo, por exemplo.

6 Em nenhuma das classificações, Almond (1986b) apresenta uma conceituação/explicação de cada categoria, mas sim, tão somente a exemplificação de modalidades pertinentes a cada qual. A equivalência, assim, é identificada, quando não na própria nomenclatura, nos exemplos dados por cada autor.

7 Visando a especificidade, poderia ser incluída também uma categoria quaternária, dividindo os jogos, por exemplo, entre individuais e coletivos (podendo-se considerar também, os semicoletivos, que seriam aqueles em que há mais de um jogador em cada equipe, mas nos quais a ação ofensiva é executada exclusivamente individualmente, sem possibilidade de troca de passes, como no caso da peteca ou do tênis em duplas, por exemplo) ou a partir de outros critérios, como feito nos exemplos de jogos com interação entre adversários, de território e progressão com móbil.

8 Esta categoria pode ser suprimida da classificação, vez que, dada sua especificidade, apresenta-se mais suscetível a deixar de atender a características peculiares de jogos esportivos que possam vir a surgir. Por outro lado, se for o caso de mantê-la, deve-se considerar que, no Quadro 2 foram inseridos somente critérios condizentes com os jogos esportivos já conhecidos, podendo ser acrescentados outros.

9 Considerando a limitação de espaço para um texto científico e a facilidade de acesso à informação atualmente possibilitada pela internet, os jogos esportivos citados podem ser conhecidos a partir de uma busca simples na mesma. Os nomes dos jogos encontram-se em inglês para facilitar a busca eletrônica (exceto em jogos esportivos brasileiros ou que adotam internacionalmente denominação em outro idioma). Não encontram-se elencados os jogos esportivos relativos ao paradesporto.

10 Embora possa-se utilizar também os pés, entende-se que o jogo é predominantemente praticado com as mãos, sendo o uso dos pés um bônus na pontuação.

11 Pebolim e Futebol de Mesa tratam-se de jogos esportivos bastante peculiares. Embora o Pebolim simule jogos esportivos de território e haja participação simultânea, a própria disposição das peças impede que um jogador roube a bola do outro. Além disso, como as peças não avançam para frente ou para trás, não há invasão de território. No caso do Futebol de Mesa, embora também simule jogos de território e exista a possibilidade de invasão da "quadra" adversária, a participação dos jogadores é alternada. Por suas peculiaridades e por permitirem, cada qual à sua maneira, apenas uma interação indireta entre os adversários, diferentemente do que ocorre nos "jogos com interação entre adversários, de território e progressão com móbil”, estão sendo categorizados aqui como “jogos meramente de precisão ou alvo". Entretanto, reconhece-se que seria necessária a inclusão de uma categoria quaternária, diferenciando-os dos demais jogos esportivos de mesa citados e, inclusive, diferenciando-os entre si.

12 Este jogo conjuga o objetivo de acerto ao alvo com o de qualidade acrobática dos toques na bola. Como o objetivo principal é o acerto ao alvo, optou-se por inseri-lo na categoria de "jogos meramente de precisão ou alvo".

\section{BY-NC-SA}

